\title{
Microstructure and selected mechanical properties of aged Ti-15Zr-based alloys for biomedical applications
}

\author{
D.R.N. Correa ${ }^{\mathrm{a}, \mathrm{b}}$, P.A.B. Kuroda ${ }^{\mathrm{b}, \mathrm{c}}$, M.L. Lourenço ${ }^{\mathrm{b}, \mathrm{c}}$, M.A.R. Buzalaf ${ }^{\mathrm{d}}$, M.E. Mendoza, ${ }^{\mathrm{e}, \mathrm{f}}$ \\ B.S. Archanjo ${ }^{\mathrm{e}}$, C.A. Achete ${ }^{\mathrm{e}}$, L.A. Rocha ${ }^{\mathrm{b}, \mathrm{c}}$, C.R. Grandini ${ }^{\mathrm{b}, \mathrm{c}, *}$ \\ ${ }^{\text {a }}$ Federal Institute of Education, Science and Technology (IFSP), 18095-410 Sorocaba, SP, Brazil \\ ${ }^{\mathrm{b}}$ Universidade Estadual Paulista (UNESP), Laboratório de Anelasticidade e Biomateriais, 17.033-360 Bauru, SP, Brazil \\ ${ }^{\mathrm{c}}$ Institute of Biomaterials, Tribocorrosion and Nanomedicine - Brazilian Branch (IBTN/Br), 17.033-360 Bauru, SP, Brazil \\ d Universidade de São Paulo (USP), Faculdade de Odontologia, Departamento de Ciências Biológicas, 17.012-901 Bauru, SP, Brazil \\ e National Institute of Metrology Quality and Technology, Metrology Materials Division (INMETRO), 25250-020 Duque de Caxias, RJ, Brazil \\ ${ }^{\mathrm{f}}$ Universidad Pedagógica y Tecnológica de Colombia, Grupo de Investigación en Materiales Siderúrgicos, 150003 Boyacá, Colombia
}

\section{A R T I C L E I N F O}

\section{Keywords:}

Titanium alloys

Aging

Microstructure

Mechanical properties

\begin{abstract}
A B S T R A C T
In this study, Ti-15Zr-xMo $(5,10,15$, and $20 \mathrm{wt} \%)$ alloys were submitted to solution and aging treatments and their effects evaluated in terms of phase composition and selected mechanical properties (Vickers microhardness and Young's modulus) for use as biomedical implants. The solution treatment was performed at $1123 \mathrm{~K}$ for $2 \mathrm{~h}$, while aging treatments were carried out at $698 \mathrm{~K}$ for 4,8 , and $12 \mathrm{~h}$, followed by water quenching. Phase composition and microstructure were dependent of the heat treatments, with Ti-15Zr-5Mo ( $\alpha+\beta$ type) and Ti15Zr-10Mo (metastable $\beta$ type) alloys exhibiting intense $\alpha$ phase precipitation. The $\alpha$-phase precipitates were related to $\alpha^{\prime \prime} \rightarrow \alpha$ and $\beta \rightarrow \alpha$ phase decompositions. The Ti-15Zr-10Mo alloy exhibited an intermediary isothermal $\omega$-phase precipitation after aging for $4 \mathrm{~h}$. Vickers microhardness and Young's modulus values changed gradually with the amount of $\alpha$ phase. Aged Ti-15Zr-15Mo and Ti-15Zr-20Mo alloys presented better combinations of hardness and Young's modulus than CP-Ti and Ti-64 ELI for biomedical applications.
\end{abstract}

\section{Introduction}

Titanium (Ti) and its alloys have been extensively employed as biomaterials specially in dental and orthopedical implants due to their well-suited properties, such as appropriate corrosion resistance, relatively low Young's modulus, high strength-to-density ratio, and recognized biocompatibility [1, 2]. In despite of the fact that Young's modulus values of novel Ti-based alloys (60-100 GPa) are closer to hard tissues (10-30 GPa), which makes it possible to avoid bone atrophy and the stress-shielding effect [3, 4], their mechanical strength should be adequate to support biomechanical loads along the life span of the implant $[5,6]$. By alloying elements and heat treatments, novel biomedical Ti-based alloys are being developed that combine a low Young's modulus and high mechanical strength [5, 7].

Alloying elements and heat treatments plays an important role in the microstructure-properties relationship in Ti-based alloys, since phase precipitation mechanisms are intrinsically dependent on the composition and processing steps [8]. Zirconium ( $\mathrm{Zr}$ ) is considered a neutral element, although recent research has indicated that it has a $\beta$ stabilizer action when in a solid solution with another $\beta$-stabilizer element [9-11]. Molybdenum (Mo) is a strong $\beta$-stabilizer that could fully retain $\beta$ phase at $10 \mathrm{wt} \%$ after water quenching. Moreover, the addition of Mo can decrease Young's modulus and improve the corrosion resistance of the material $[12,13]$. In previous studies, we have found low Young's modulus $(60-80 \mathrm{GPa})$, high tribocorrosion resistance, and good cell viability in Ti-15Zr-Mo alloys [9, 14-16]. In particular, the Ti-15Zr-15Mo alloy displayed the best potential for biomedical application.

Aging is an industrially applied heat treatment in Ti-based alloys which improves their mechanical strength through secondary phase precipitation [2, 17, 18]. $\beta$-type Ti-based alloys exhibited $\alpha$-phase precipitation along the $\beta$-phase matrix when submitted to aging treatments, which results in high mechanical and fatigue strength $[19,20]$. Tane et al. [20] obtained an enhancement in the elastic components (bulk and shear modulus) of metastable $\beta$-type Ti-Nb-based alloys after room temperature aging, which resulted in interesting properties for biomedical applications. Li et al. [21] studied the effect of aging treatment in Ti-Nb-Zr-based alloys, obtaining improvements in the superelastic and mechanical properties of the alloy for use as metallic implants. Similarly, Liang et al. [22] obtained a low Young's modulus

\footnotetext{
* Corresponding author at: Universidade Estadual Paulista (UNESP), Laboratório de Anelasticidade e Biomateriais, 17.033-360 Bauru, SP, Brazil

E-mail address: betog@fc.unesp.br (C.R. Grandini).
} 

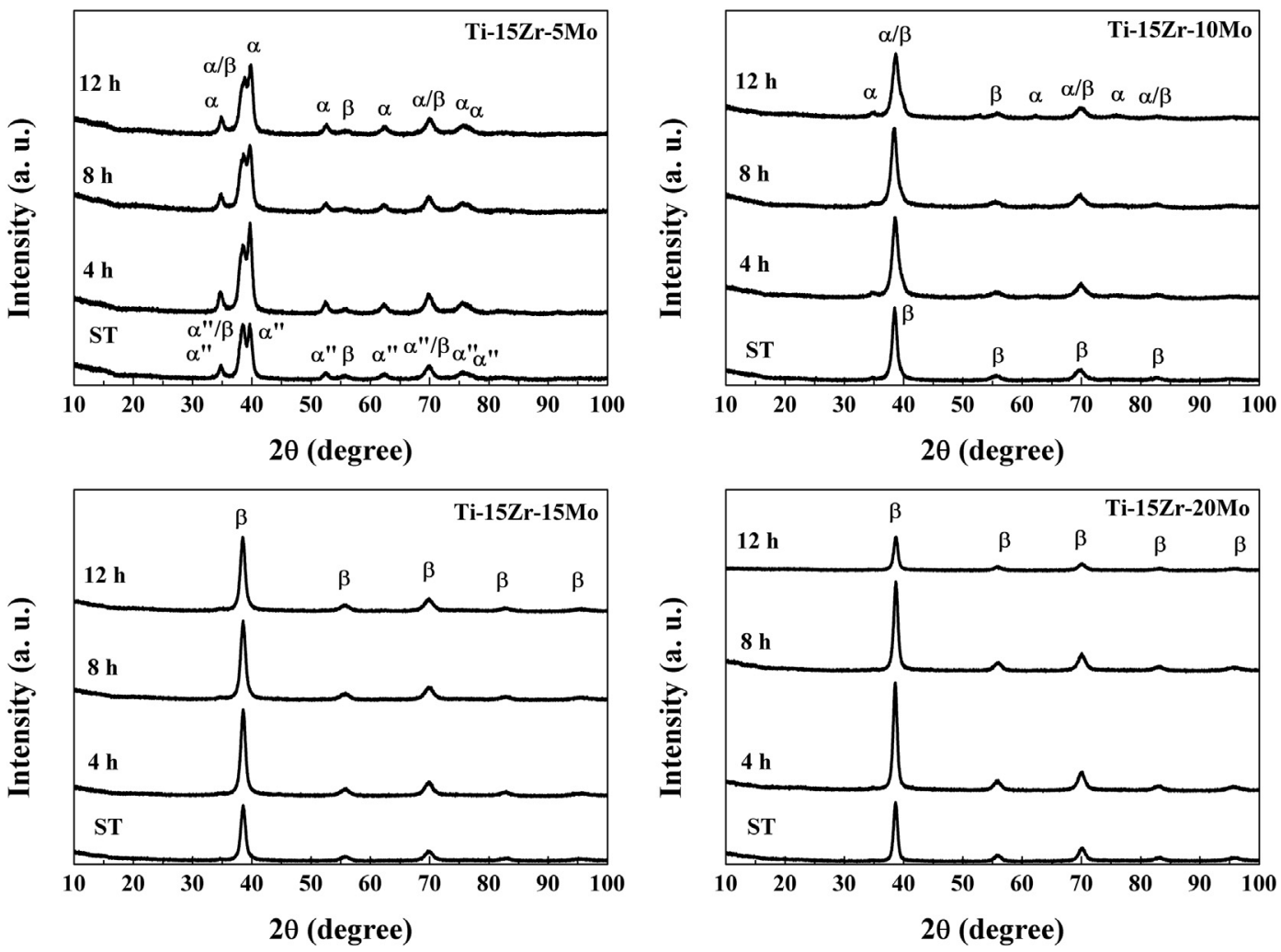

Fig. 1. XRD patterns for Ti-15Zr-Mo alloys.

Table 1

Rietveld parameters for Ti-15Zr-Mo alloy.

\begin{tabular}{llllll}
\hline Alloy & Condition & Gof $^{\mathrm{a}}$ & $\mathrm{R}_{\exp }(\%)^{\mathrm{a}}$ & $\mathrm{R}_{\mathrm{wp}}(\%)^{\mathrm{a}}$ & $\mathrm{R}_{\mathrm{p}}(\%)^{\mathrm{a}}$ \\
\hline \multirow{2}{*}{ Ti-15Zr-5Mo } & $\mathrm{ST}$ & 1.743 & 9.78 & 8.42 & 6.51 \\
& $4 \mathrm{~h}$ & 1.928 & 8.02 & 7.75 & 6.00 \\
& $8 \mathrm{~h}$ & 1.754 & 8.80 & 7.29 & 5.64 \\
Ti-15Zr-10Mo & ST & 1.875 & 9.28 & 7.57 & 5.94 \\
& $4 \mathrm{~h}$ & 1.668 & 9.08 & 8.33 & 6.49 \\
& $8 \mathrm{~h}$ & 1.603 & 7.15 & 6.74 & 5.22 \\
Ti-15Zr-15Mo & 1.561 & 9.93 & 6.63 & 5.15 \\
& $\mathrm{ST}$ & 1.587 & 7.91 & 6.88 & 5.43 \\
& $4 \mathrm{~h}$ & 1.869 & 7.07 & 8.83 & 6.80 \\
& $8 \mathrm{~h}$ & 1.795 & 6.16 & 6.76 & 5.33 \\
Ti-15Zr-20Mo & $12 \mathrm{~h}$ & 1.677 & 5.77 & 6.70 & 5.27 \\
& $\mathrm{ST}$ & 1.745 & 8.39 & 6.96 & 5.47 \\
& $4 \mathrm{~h}$ & 1.902 & 8.46 & 7.91 & 6.13 \\
& $8 \mathrm{~h}$ & 1.756 & 8.51 & 6.83 & 5.50 \\
& $12 \mathrm{~h}$ & 1.561 & 8.27 & 10.22 & 8.07 \\
\hline
\end{tabular}

${ }^{\text {a }}$ Godness of fitness (GoF or $\left.\chi^{2}\right)$; Expected residual factor $\left(\mathrm{R}_{\text {exp }}\right)$; Weightedprofile residual factor $\left(\mathrm{R}_{\mathrm{wp}}\right)$; Parametric or Bragg residual factor $\left(\mathrm{R}_{\mathrm{p}}\right)$.

and large plasticity in Ti-Nb-Zr-Mo alloy by combining theoretic compositional approach and aging treatment.

This study aims to analyze the effect of aging time in the structure, microstructure, and selected mechanical properties of Ti-15Zr-xMo alloys (at $5,10,15$, and $20 \mathrm{wt} \%$ ) for use as biomaterial. Aging treatments were performed to induce $\alpha$-phase precipitation, increase mechanical strength, and maintain a low Young's modulus for use as biomedical implants.

\section{Materials and methods}

Ti-15Zr-xMo alloys (at 5, 10, 15 and $20 \mathrm{wt} \%$ ) were produced by argon arc melting from commercially pure metals: CP-Ti (grade 2), pure $\mathrm{Zr}$ (99.8\%), and pure Mo (99.9\%). The ingots were molded in plate-type samples by air-cooled hot rolling at $1273 \mathrm{~K}$, followed by annealing treatment at $1273 \mathrm{~K}$ in a vacuum of $10^{-5}$ Torr for $24 \mathrm{~h}$ with slow cooling. Afterwards, the samples were submitted to solution treatment (ST) at $1123 \mathrm{~K}$ in a vacuum of $10^{-6}$ Torr for $2 \mathrm{~h}$ with water quenching. Aging treatments were subsequently carried out at $698 \mathrm{~K}$, with a heating rate of $10 \mathrm{~K} / \mathrm{min}$ from room temperature, in a vacuum of $10^{-6}$ Torr for $4 \mathrm{~h}, 8 \mathrm{~h}$, and $12 \mathrm{~h}$ with water quenching. All heat treatments were conducted in a quartz tube. The chemical composition of the samples can be found in previous reports, where it is shown the alloying elements remained within a deviation range of $1 \mathrm{wt} \%$ from the nominal composition, and the $\mathrm{O}$ and $\mathrm{N}$ interstitial gases presented values around $0.20-0.30 \mathrm{wt} \%$ and $0.02-0.04 \mathrm{wt} \%$., respectively [12].

The phase composition was evaluated by X-ray diffraction measurements (XRD) (Rigaku D/Max 2100/PC diffractometer). XRD patterns were acquired by the powder method at $40 \mathrm{kV}$ and $20 \mathrm{~mA}$, between $10^{\circ}$ and $100^{\circ}$, with a step size of $0.02^{\circ}$ and a time per step of $3.2 \mathrm{~s}$, using monochromatic $\mathrm{CuK}_{\alpha}$ radiation $(\lambda=0.1544 \mathrm{~nm})$. The results were analyzed by the Rietveld method throughout standard crystallographic sheets and the GSAS/EXPGUI program. A standard $\mathrm{Y}_{2} \mathrm{O}_{3}$ sample was used to obtain the instrumental parameters of the equipment [23].

Microstructural analysis was performed by optical microscopy (OM) (Olympus BX51M microscope), scanning electron microscopy (SEM) (EVO LS15 Carl Zeiss microscope) and transmission electron microscopy (TEM) (Titan FEI microscope). Chemical micro-analysis was performed by energy-dispersive X-ray spectroscopy (EDS) (Oxford detector) coupled in the SEM equipment. The samples were submitted to a metallographic process by grinding with silicon carbide (SiC) waterproof sandpapers; polishing with a colloidal solution of alumina and diamond; and etching with $\mathrm{H}_{2} \mathrm{O}, \mathrm{HNO}_{3}$, and $\mathrm{HF}$ solution (80:15:5). For TEM analysis, the samples were previously prepared in thin foils by a dual beam Quanta 3D SEM instrument with $\mathrm{Ga}^{+}$source and organometallic gas of $\mathrm{PtCO}_{6}$. The samples were analyzed by TEM in a $\mathrm{C}_{s}$ corrected FEI Titan 80-300 (300 kV operation voltage) equipped with a $\mathrm{X}$-FEG filament and monochromator. Selected area electron diffraction 


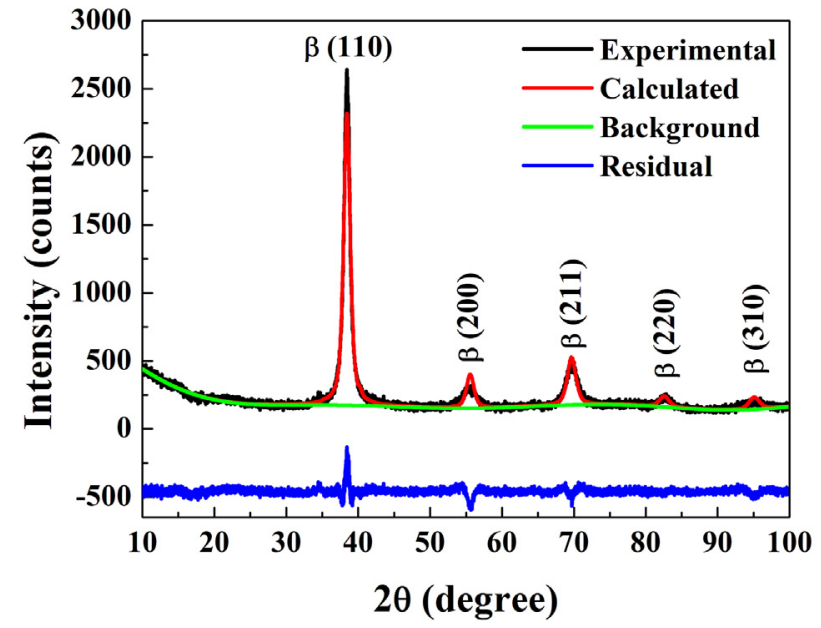

Fig. 2. Refined pattern of ST Ti-15Zr-10Mo alloy.

patterns (SAED) were acquired in a parallel mode. The images were analyzed using the Digital Micrograph and MacTempas softwares.

The selected mechanical properties were evaluated by Vickers microhardness and Young's modulus measurements. Vickers microhardness measurements were performed by a Shimadzu HMV-2 microdurometer, with a load of $0.200 \mathrm{kgf}(1.961 \mathrm{~N})$ and dwell time of $30 \mathrm{~s}$. Young's modulus measurements were performed by the impulse excitation technique, using rectangular samples $(15 \mathrm{~mm} \times 5 \mathrm{~mm} \times 1 \mathrm{~mm})$. Mechanical tests followed ASTM (American Society for Testing and Materials) standard procedures E384-11e1 and E1876-09 [24, 25]. Average values were taken after 10 measurements and were compared with the CP-Ti (grade 2) and Ti-64 ELI (Ti-6Al-4V) alloys [26].

\section{Results and discussion}

The XRD patterns of the solution treated (ST) and for the aged samples (4, 8 and $12 \mathrm{~h}$ treatments) are displayed in the Fig. 1. As seen, phase composition was dependent on the alloying elements and heat treatments. The ST Ti-15Zr-5Mo alloy presented the coexistence of $\alpha^{\prime \prime}$ and $\beta$ phases as a result of water quenching from temperatures above $\beta$ transus. The aging treatment produced a slightly decrease of $(110)_{\beta}$ peak (around $38^{\circ}$ ) and increase of $(10 \overline{1} 1)_{\alpha}$ peak (around $39^{\circ}$ ). It was not possible to detect sensible differences between $\alpha^{\prime \prime} / \alpha$ proportion in the aged conditions due to the proximity of the diffraction peaks of these phases, but indexation were successfully made based on the microstructural analysis presented below. The ST Ti-15Zr-10Mo alloy exhibited only $\beta$-phase peaks, although the aged conditions provided a clear appearance of small $\alpha$-phase peaks. This suggests that the alloying elements decreased the $\beta$-transus temperature to nearly room temperature, and the aging treatment probably induced nucleation and precipitation of $\alpha$ phase. The ST Ti-15Zr-15Mo and Ti-15Zr-20Mo alloys were composed mainly by $\beta$-phase peaks, indicating that the alloying elements were enough to decrease the $\beta$-transus temperature sharply. In overall, the nucleation of $\alpha$ phase was induced mainly in $\alpha+\beta$ and metastable $\beta$-type Ti-based alloys. Nakai et al. [27] obtained similar results in the biomedical $\beta$-type Ti-29Nb-13Ta-4.6Zr alloy after aging treatment at $723 \mathrm{~K}$ for $72 \mathrm{~h}$. Cardoso et al. [28] studied the microstructural evolution of binary Ti-xMo ( $x=5,7.5,10$, and 15) alloys after aging between $523 \mathrm{~K}$ and $723 \mathrm{~K}$ for $100 \mathrm{~h}$. They found the same $\alpha$ phase precipitation in $\beta$-type Ti-10Mo and Ti-15Mo alloys with these aging temperatures.

XRD patterns were subsequently subjected to Rietveld analysis to quantify the phase compositions. The refinement parameters obtained (Table 1) were close to some previous reports, which indicates a successful structural refinement $[29,30]$. The visual plot of the ST Ti-15Zr-10Mo alloy exhibited in Fig. 2 ensures a good fit between experimental and theoretical
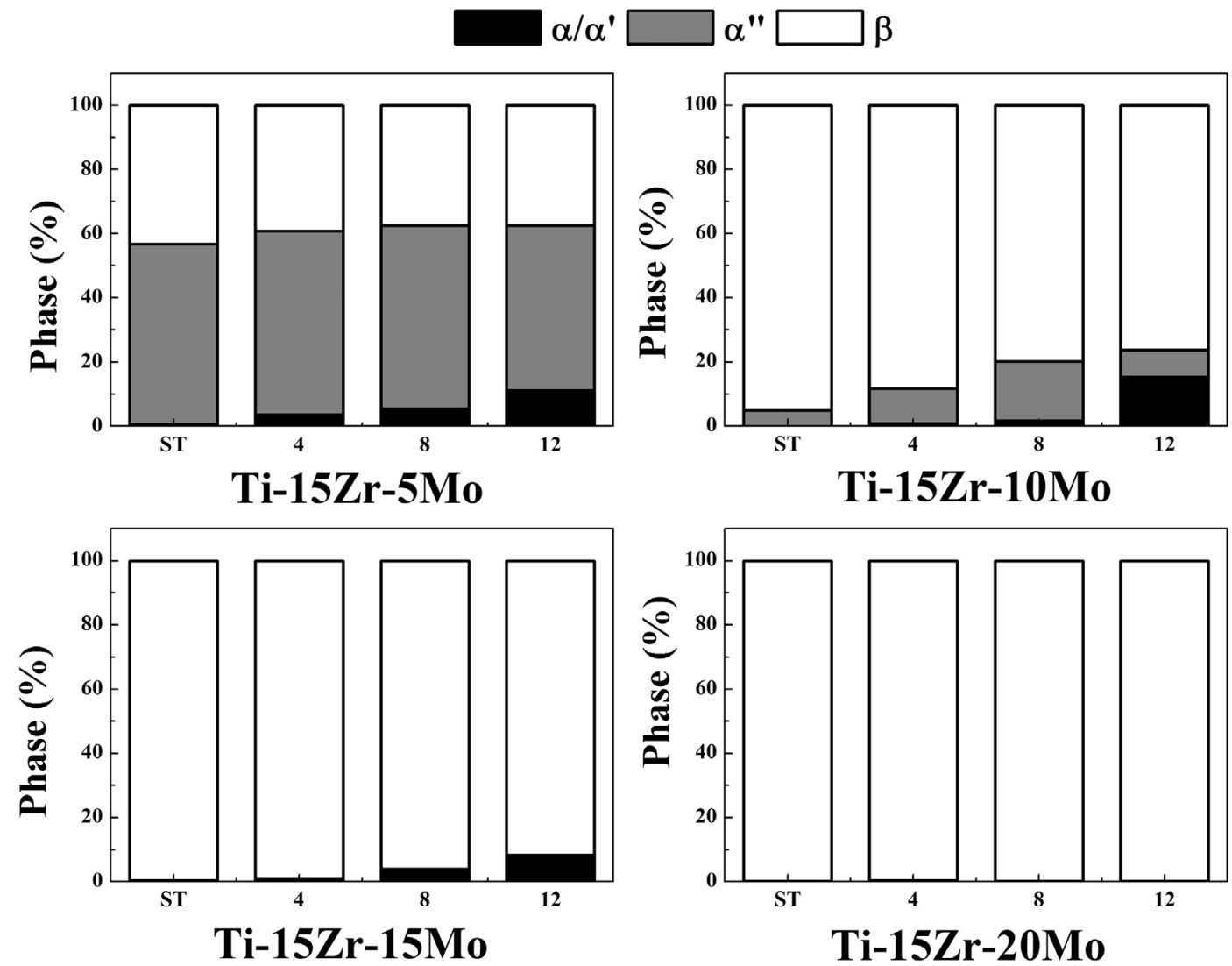

Fig. 3. Phase composition analysis for Ti-15Zr-Mo alloys. 


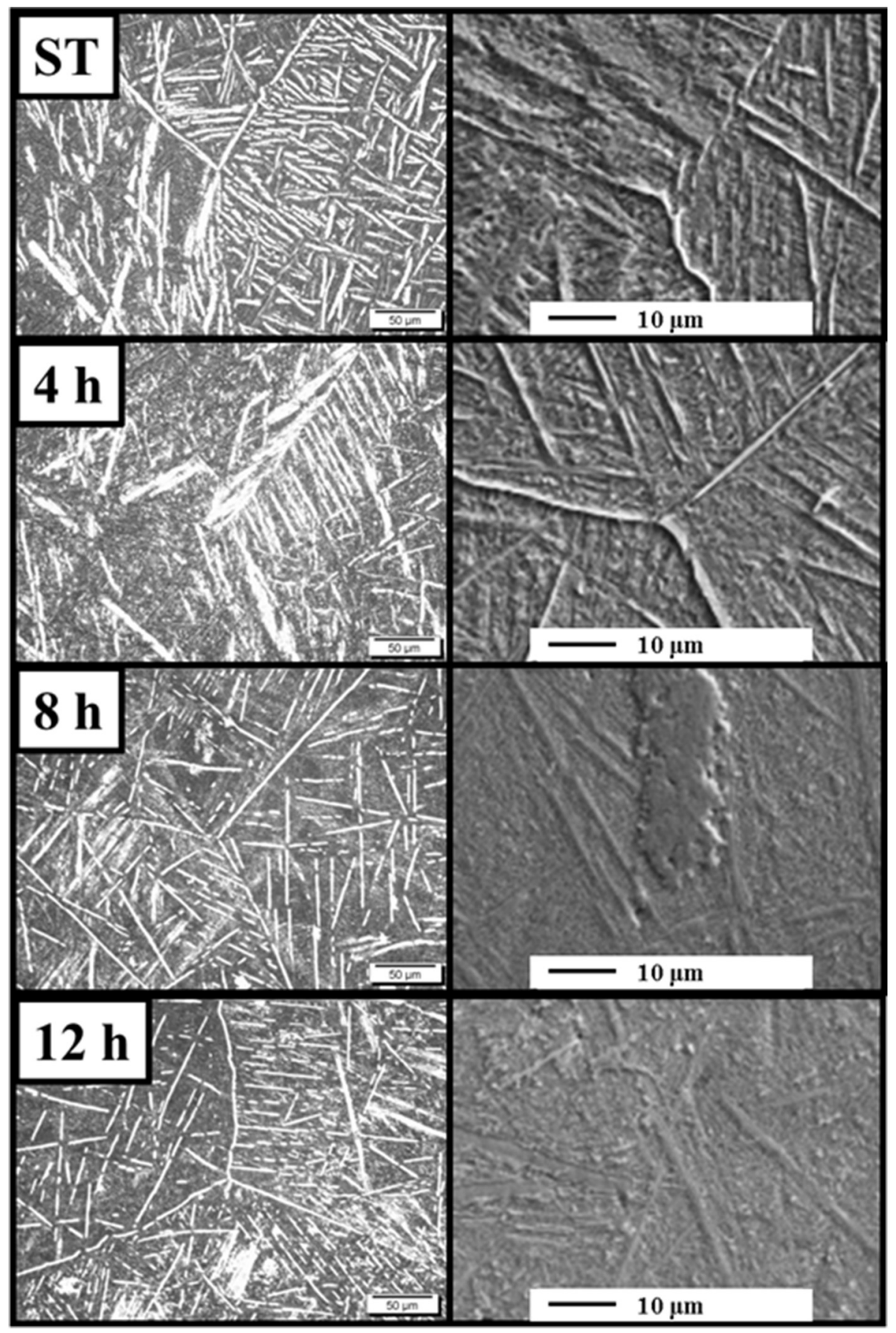

Fig. 4. Microstructural evolution of Ti-15Zr-5Mo alloy: optical micrograph (left) and secondary electron image (right).

patterns obtained after refinement [23, 31]. Similar results were obtained in all samples. The phase compositions of the ST and aged alloys are summarized in the Fig. 3. The Ti-15Zr-5Mo and Ti-15Zr-10Mo alloys exhibited small changes in the proportion of $\alpha^{\prime \prime}$ to $\beta$ with the increase of $\alpha$ phase, which indicates the coexistence of $\alpha^{\prime \prime} \rightarrow \alpha$ and $\beta \rightarrow \alpha$ phase decompositions. The suppression the martensitic phase proportion is a result of the decreasing Ms/Mf temperature close to the room temperature by the Mo content, which remained within $\alpha+\beta$ region in the pseudo-binary diagram [8]. The Ti-15Zr-15Mo alloy presented only a slight increase of $\alpha$ phase in relation to $\beta$ phase, suggesting a direct decomposition of $\beta \rightarrow \alpha$ phase, while Ti-15Zr-20Mo alloy did not presented modifications of phase composition with the aging treatments. The $\alpha$-phase nucleation and precipitation in aging treatments is dependent on heat parameters and $\beta$-transus temperature [8, 17]. Mantani et al. [19] studied $\alpha^{\prime \prime}$-phase decomposition in TisMo alloys submitted to aging at $723 \mathrm{~K}$ and $923 \mathrm{~K}$ for $2.5 \mathrm{~h}$. They found that the $\alpha^{\prime \prime}$ phase was subsequently decomposed in $\alpha$ and $\beta$ phases at high temperatures. Similar results were obtained by Zhou, Niinomi, and Akahori [32] in Ti-Ta (30-50 wt \% Ta) alloys with aging at $723 \mathrm{~K}$ and $823 \mathrm{~K}$ for $72 \mathrm{~h}$. It is worth to mention that besides the overlapped $\alpha, \alpha^{\prime}, \alpha^{\prime \prime}$ and $\beta$ phase peaks around $40^{\circ}$ were not possible to be identified separately, the Rietveld method permitted to quantify it, once it compares the samples' XRD pattern with the standard pattern of each phase individually [33]. Thus, the refinement turned possible to quantify these phases by adjusting the position, intensity and the full width at half maximum (FWHM) of each peak. It was quite useful for the case of Ti-15Zr-5Mo and Ti-15Zr-10Mo alloys, where the obtained phase compositions were in agreement with the selected mechanical properties evaluation described below.

The microstructural evolutions of the ST and aged samples are 


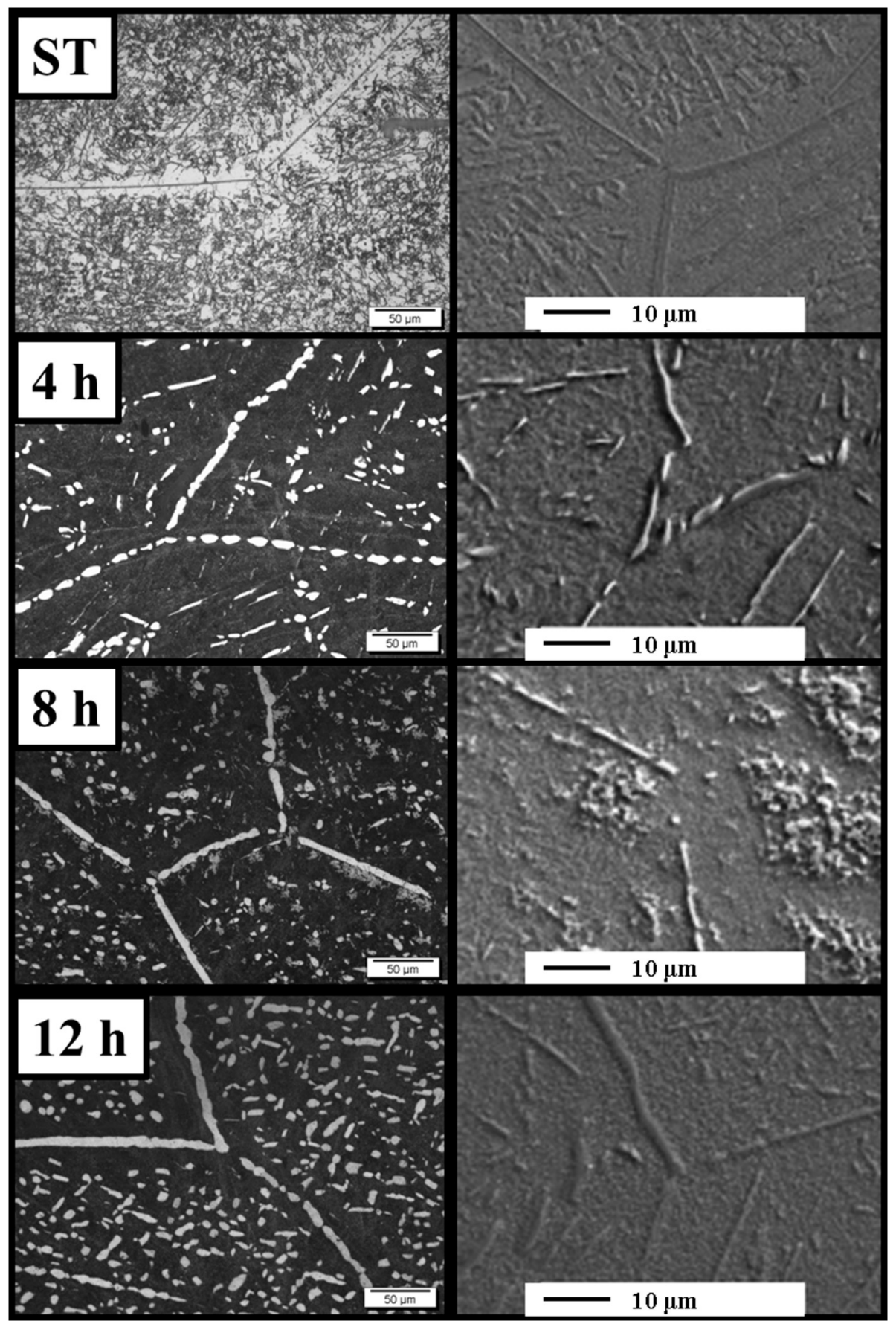

Fig. 5. Microstructural evolution of Ti-15Zr-10Mo alloy: optical micrograph (left) and secondary electron image (right).

depicted in the micrographs shown in Figs. 4 to 7. The ST Ti-15Zr-5Mo alloy (Fig. 4) was composed by $\beta$-phase grains with acicular structures of $\alpha$ " with intergranular phase distribution. The aging treatment resulted in the growth of small laths of $\alpha$ phase. In an earlier study, we investigated the microstructure and some mechanical properties of binary Ti-Zr alloys for dental applications [9]. The microstructure of Ti$15 \mathrm{Zr}$ alloy was composed by laths of martensite $\alpha^{\prime}$ phase, which were thicker than that of Ti-15Zr-5Mo, indicating $\alpha^{\prime \prime}$ phase precipitation of the last one. In addition, the differences between morphology of $\alpha^{\prime}$ and $\alpha^{\prime \prime}$ phases in Ti-Mo alloys have been extensively studied in the literature $[28,34]$. Therefore, besides the diffraction peaks of these phases were closer, the microstructural analysis confirmed the phase indexation performed. The metastable $\beta$-type Ti-15Zr-10Mo alloy (Fig. 5) presented $\beta$-phase grains permeated with small amounts of acicular structures of $\alpha$ " phase in the ST sample. After aging, the acicular structures were clearly changed to globular and lath-shaped precipitates of $\alpha$ phase. The amount of $\alpha$-phase gradually increased with the aging time. The ST Ti-15Zr-15Mo alloy (Fig. 6) exhibited only equiaxed $\beta$-phase grains, although small precipitates of $\alpha$ phase started to appear along the grain boundaries after aging treatments. The precipitates began to form at the grain boundaries and later to the intergranular region with the increase of aging time. EDS analysis at the grain boundary (Fig. 8) indicated that the precipitates were composed of relatively high amounts of oxygen compared to the intergranular region, while the relative carbon content remained almost the same, suggesting that the $\alpha$ phase was induced exclusively by interstitial elements diffusion near grain boundaries in the aging treatments. Mashandi and Dippenaar [35] observed the same mechanism in the Ti-5Al- 


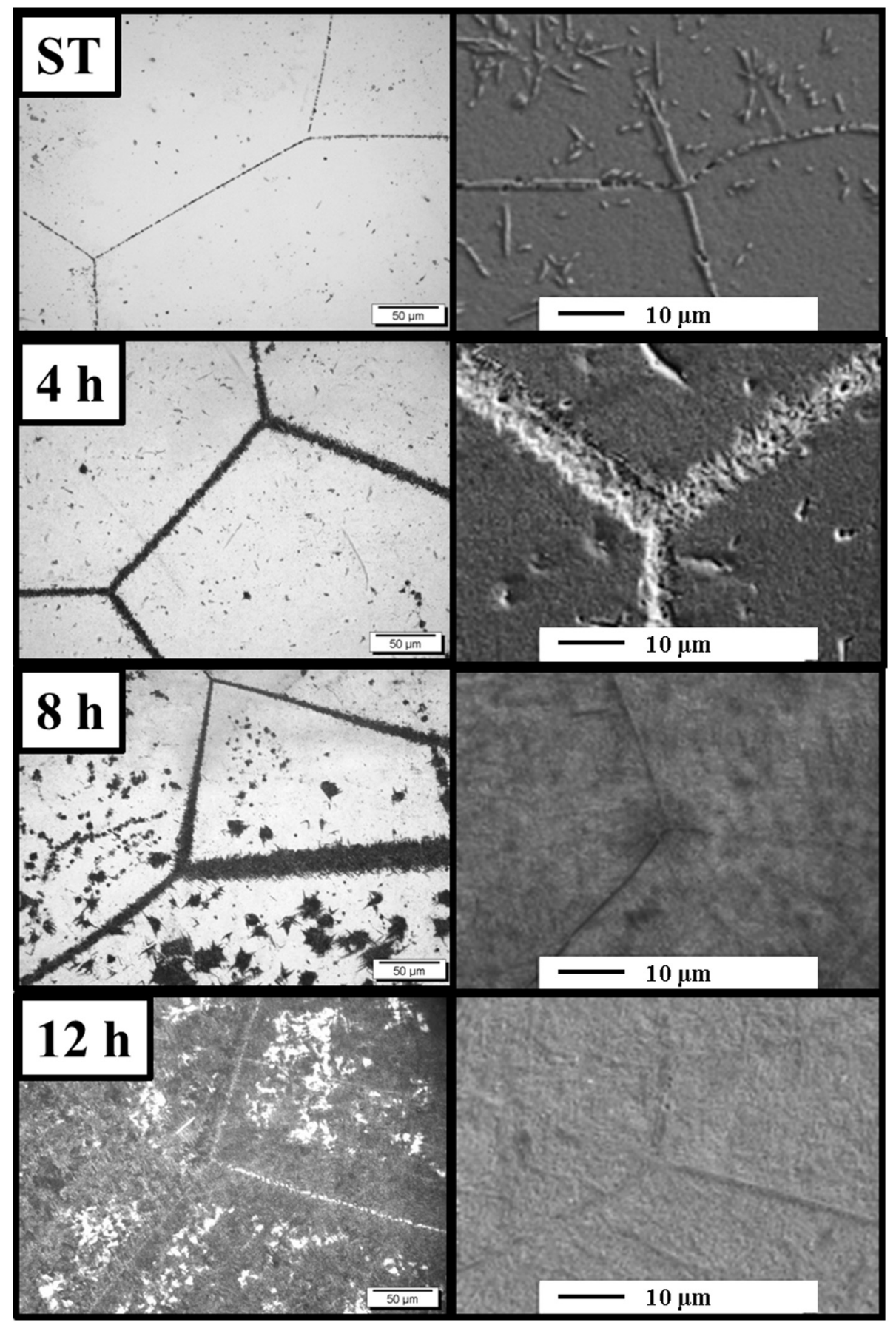

Fig. 6. Microstructural evolution of Ti-15Zr-15Mo alloy: optical micrograph (left) and secondary electron image (right).

5Mo-5V-3Cr alloy (Ti-5553) when submitted to an aging treatment at $673 \mathrm{~K}$ between $0.5 \mathrm{~h}$ and $8 \mathrm{~h}$. The Ti-15Zr-20Mo alloy (Fig. 7) did not present noticeable differences with the aging treatments, with a microstructure that had only equiaxed $\beta$-phase grains. This result was expected once there was enough alloying elements to decrease the $\beta$ transus temperature close to the room temperature [36].

The Vickers microhardness and Young's modulus values of the ST and aged samples are exhibited in the Fig. 9. Regarding Vickers microhardness, the Ti-15Zr-5Mo and Ti-15Zr-20Mo alloys presented a slight decrease with the aging time, while the Ti-15Zr-10Mo and Ti15Zr-15Mo alloys exhibited a sharp increase with aging at $4 \mathrm{~h}$, followed by a decrease. For the Ti-15Zr-5Mo alloy, the decrease could be related to the softer characteristic of $\alpha$-phase precipitation in comparison to the $\alpha^{\prime \prime}$ and $\beta$ phases [37]. However, in the case of the Ti-15Zr-20Mo alloy, the decrease might be related to the interstitial diffusion in the microstructure, as interstitial elements in the grain boundaries tend to 


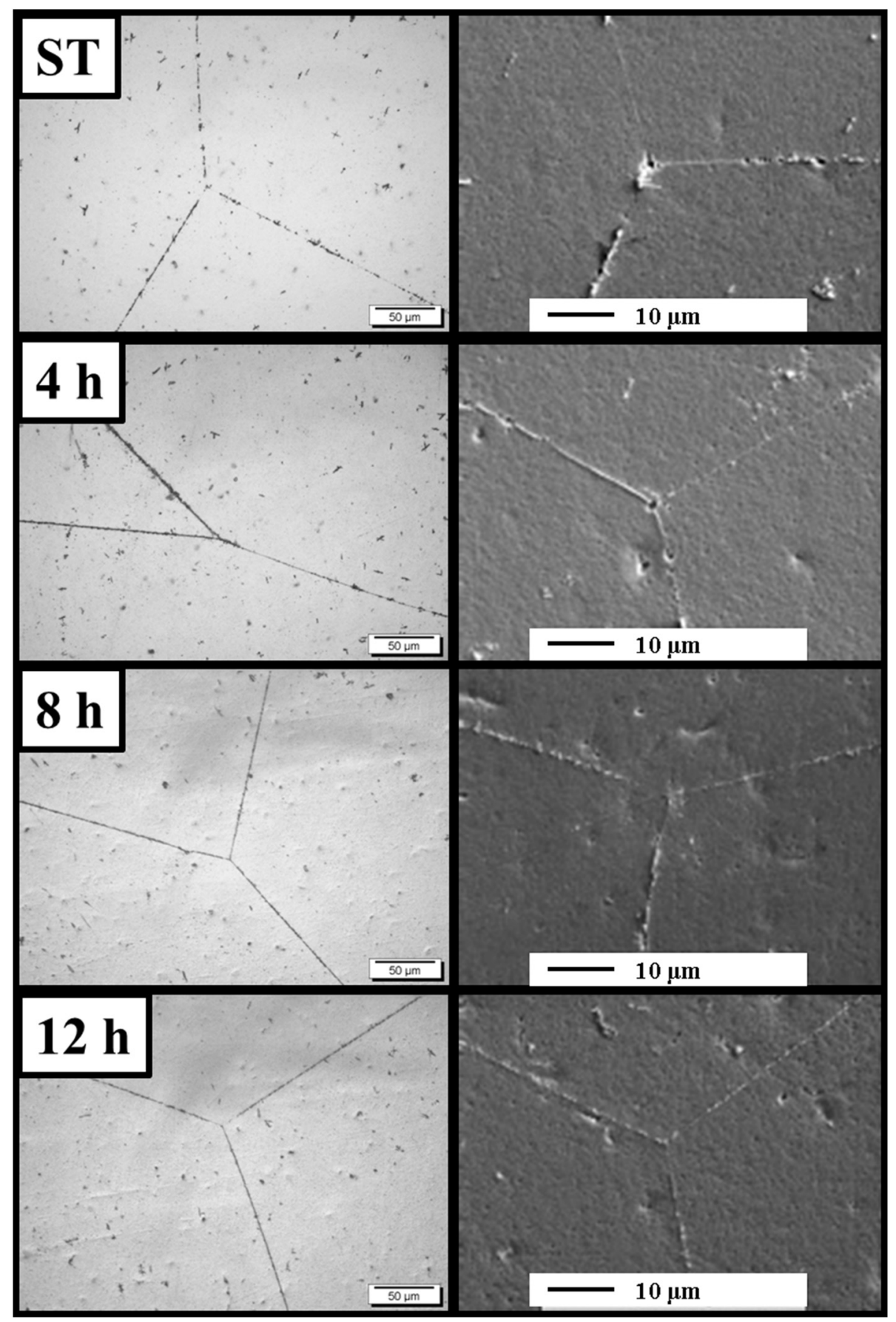

Fig. 7. Microstructural evolution of Ti-15Zr-20Mo alloy: optical micrograph (left) and secondary electron image (right).

suppress plastic deformation during mechanical loads [38]. For the Ti15Zr-10Mo and Ti-15Zr-15Mo alloys, the increased hardness with $4 \mathrm{~h}$ of aging could be related to the nucleation of intermediary isothermal $\omega$ phase, which has the highest hardness values within Ti phases. The abrupt increase of the hardness of the Ti-15Zr-10Mo alloy suggests that a high amount of isothermal $\omega$ phase could be precipitated, which would be difficult to detect by XRD and SEM techniques due its nanometric size [2]. The subsequent decrease of hardness can be related to the classical formation of $\alpha$ phase nucleated from $\omega$ phase precipitates, as described by previous studies [21, 39, 40]. Young's modulus values were also sensible to aging. The Ti-15Zr-5Mo and Ti-15Zr-15Mo alloys presented a gradual increase of Young's modulus values due to the ascribed $\alpha$-phase precipitation, which has higher values than the $\alpha$ " and $\beta$ phases. The Ti-15Zr-20Mo alloy displayed a similar increase, related to the same mechanism of interstitial diffusion in the $\beta$-phase grains [41]. Instead Ti-20Mo alloys exhibits isothermal $\omega$ phase after appropriate aging treatment [42], it was not observed evidences of precipitation in the Ti-15Zr-20Mo alloys through its mechanical properties evolution. 

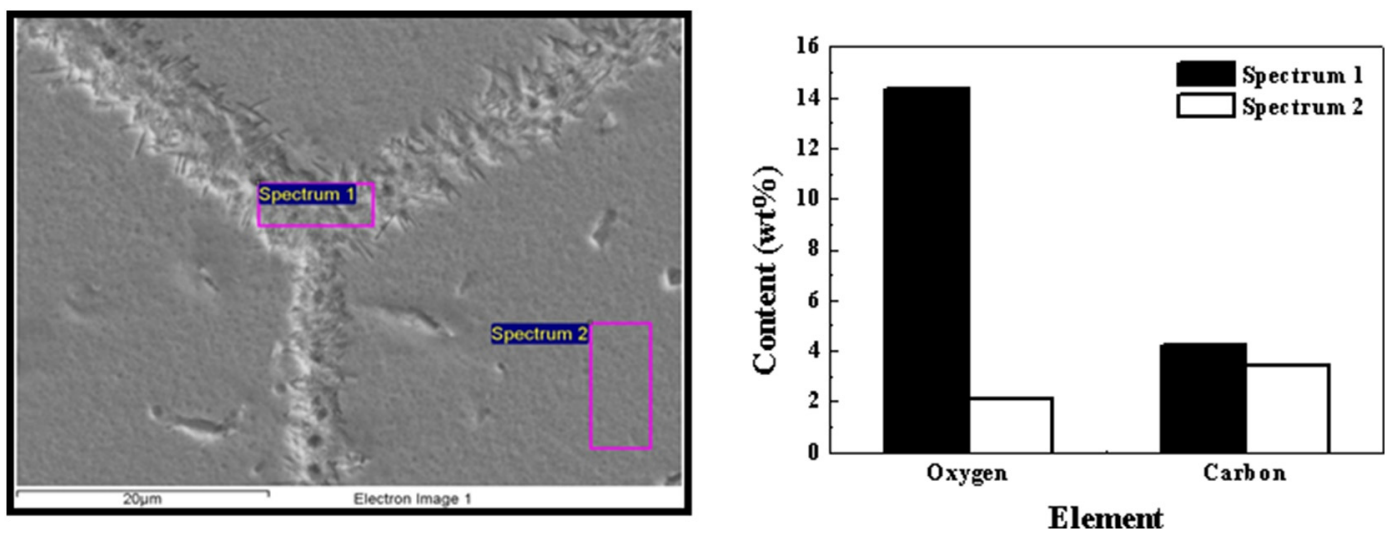

Fig. 8. EDS analysis of aged Ti-15Zr-15Mo alloy (4h).

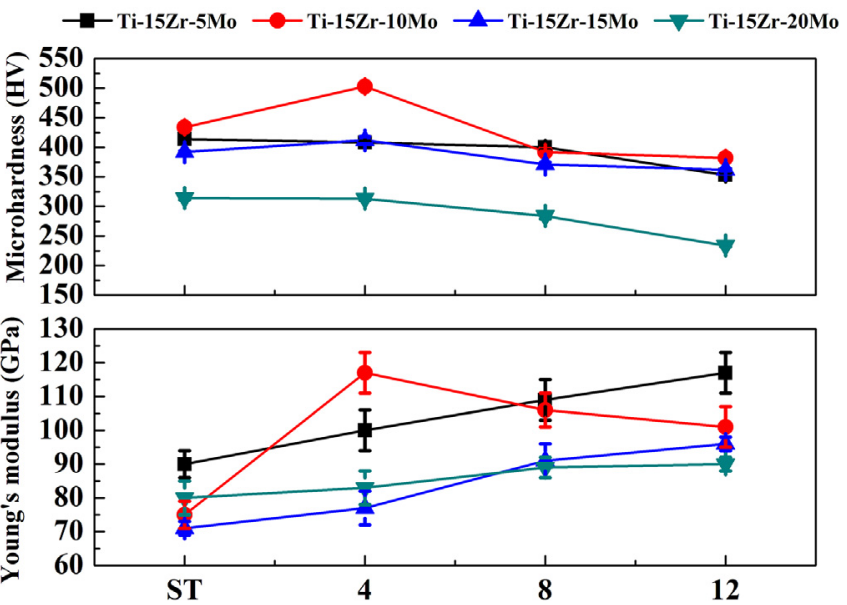

Fig. 9. Selected mechanical properties for Ti-15Zr-Mo alloys.

The high amount of isothermal $\omega$ phase of Ti-15Zr-10Mo produced a robust increase of Young's modulus values after aging for $4 \mathrm{~h}$. In order to confirm the presence of an isothermal $\omega$ phase, TEM analysis was performed in the aged Ti-15Zr-10Mo alloy after $4 \mathrm{~h}$ (Fig. 10). In the Fig. 10a and b are shown the BF and DF images of the sample, where it can be seen a $\beta$ phase matrix crossed by a large $\alpha$ phase plate. It is possible to observe that fine dark points are distributed in the intergranular $\beta$ phase region. The SAED pattern (Fig. 10c) was taken in this region, resulting in clear $\beta$ phase spots with $\omega$ phase reflections at $1 / 3$ and $2 / 3$ distances of the $[110]_{\beta}$ zone axis (Fig. 10d). Nucleation and precipitation of $\alpha$ phase from the isothermal $\omega$ phase have been observed in several studies. For example, Cardoso et al. [28] detected $\omega$ phase precipitation in aged Ti-10Mo alloy at $523 \mathrm{~K}$ for $100 \mathrm{~h}$, which reflected in high hardness values. With long aging times, the amount of $\omega$ phase decomposed into $\alpha$ phase. And also, Ferrandini et al. [43] detected a pronounced increase of Vickers microhardness due to the $\omega$ phase precipitation in aged Ti-35Nb-7Zr-5Ta and Ti-35Nb-7Ta alloys. Although the nucleation of isothermal $\omega$ phase is dependent of the alloy composition and aging time, the aging temperature takes an important role in its precipitation, once high temperatures favors the direct formation of $\alpha$ phase [2]. In a similar way, Xavier [44] performed aging treatment in Ti-15Zr-xMo $(\mathrm{x}=0,5,10$ and $15 \mathrm{wt} \%)$ alloys at $873 \mathrm{~K}$ for $6 \mathrm{~h}, 12 \mathrm{~h}$ and $24 \mathrm{~h}$. It was observed a direct phase transformation of $\beta \rightarrow$ $\alpha$ without intermediary $\omega$ phase precipitation. It reflected in a decrease of Vickers microhardness values. Therefore, it is possible to notice that the aging temperature of the present study (698 K) is within the range of $\omega$ phase precipitation [2, 7], and also both alloying elements ( $\mathrm{Zr}$ and Mo) are playing role in the mechanisms of $\omega$ phase precipitation [21, 45].

The aged Ti-15Zr-15Mo and Ti-15Zr-20Mo alloys displayed a combination of high Vickers microhardness and low Young's modulus, more so than the CP-Ti $(187 \pm 4 \mathrm{HV}, 109 \pm 2 \mathrm{GPa})$ and Ti-64 ELI alloys $(289 \pm 4 \mathrm{HV}, 117 \pm 4 \mathrm{GPa})$, due to a combination of solid-solution and phase precipitation hardening. Assuming that hardness has a direct relation with mechanical strength [46], we can conclude that the alloys described here have great potential to be used as biomedical materials. The studied alloys might have particular potential as dental and orthopedical implants, where mechanical properties are crucial requirements [47, 48]. In addition, the obtained results could enlighten the combined role of the alloying elements ( $\mathrm{Zr}$ and $\mathrm{Mo}$ ) and the aging treatments on the phase transformation of Ti-based alloys. And finally, the aging effects on the fatigue and corrosion properties in these alloys could be an interesting scope for further investigations.

\section{Conclusions}

The effect of aging time in phase composition, microstructure, and selected mechanical properties of Ti-15Zr-xMo $(x=5,10,15$, and $20 \mathrm{wt} \%$ ) alloys were evaluated. From the results obtained, it is possible to summarize the following:

- XRD patterns indicated that an amount of $\alpha$ phase (less than 20\%) was precipitated in the microstructure of the aged Ti-15Zr-5Mo and Ti-15Zr-10Mo alloys;

- Phase composition evolution verified by Rietveld's refinement showed that a possible $\alpha^{\prime \prime} \rightarrow \alpha$ and $\beta \rightarrow \alpha$ phase decomposition could be taking place in the alloys;

- Microstructural analysis showed that aging promoted nucleation and the growth of globular and lath-shaped $\alpha$ phase along the $\beta$ phase grains;

- EDS analysis of the aged Ti-15Zr-15Mo alloy indicated that the $\alpha$ phase growth was induced by interstitial diffusion of oxygen from grain boundaries;

- Vickers microhardness and Young's modulus values were dependent on aging times as a result of $\alpha$ phase precipitation;

- The Ti-15Zr-10Mo alloy exhibited an abrupt increase in the selected mechanical properties after aging at $4 \mathrm{~h}$, which was related to an precipitation of isothermal $\omega$ phase; and

- The aged Ti-15Zr-15Mo and Ti-15Zr-20Mo alloys displayed the best combination of hardness and Young's modulus for dental and orthopedical implants. 


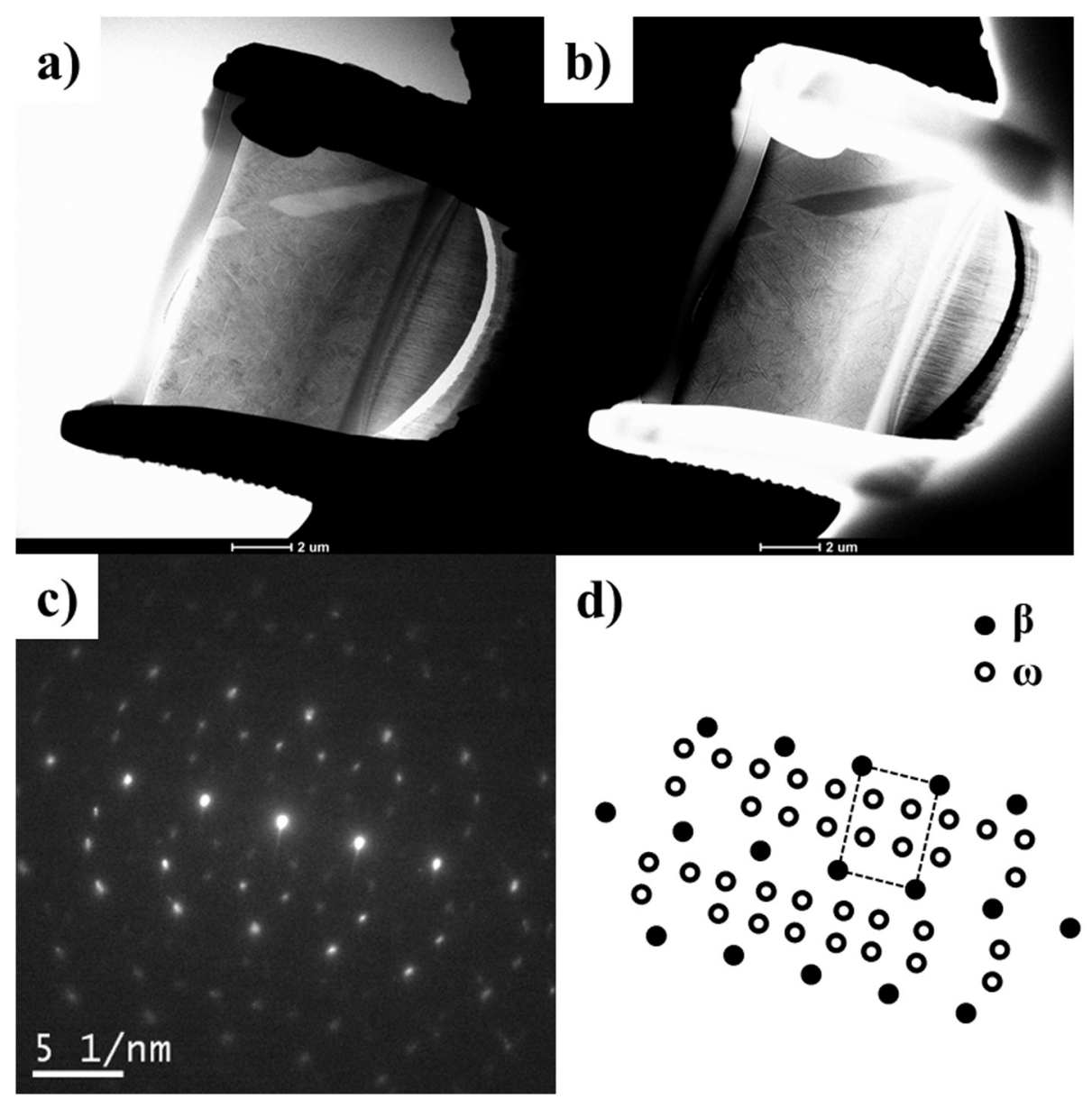

Fig. 10. TEM analysis of aged Ti-15Zr-10Mo alloy ( $4 \mathrm{~h})$ : a) BF and b) DF images of the sample, c) SAED pattern with zone axis parallel to $[110]_{\beta}$ and d) key-diagram.

\section{Acknowledgements}

The authors thank the Physics Department at UNESP's School of Sciences for providing access to its XRD and SEM equipment. This study was supported by FAPESP (grants \#2010/20440-7; \#2015/00851-6, and \#2014/22689-3), CNPq (grants \#481.313/2012-5, \#307.279/ 2013-8 and \#490.761/2013-5) and CAPES (grant \#99999.008666/ 2014-08).

\section{References}

[1] Y. Li, C. Yang, H. Zhao, S. Qu, X. Li, Y. Li, New developments of Ti-based alloys for biomedical applications, Materials 7 (2014) 1709-1800.

[2] D. Banerjee, J.C. Williams, Perspectives on titanium science and technology, Acta Mater. 61 (2013) 844-879.

[3] M. Geetha, A.K. Singh, R. Asokamani, A.K. Gogia, Ti based biomaterials, the ultimate choice for orthopaedic implants, Prog. Mater. Sci. 54 (2009) 397-425.

[4] M. Niinomi, Y. Liu, M. Nakai, H. Liu, H. Li, Biomedical titanium alloys with Young's moduli close to that of cortical bone, Regen. Biomater. (2016) rbw016, http://dx. doi.org/10.1093/rb/rbw016.

[5] Y. Kirmanidou, M. Sidira, M.E. Drosou, V. Bennani, A. Bakopoulou, A. Tsouknidas, N. Michailidis, K. Michalakis, New Ti-alloys and surface modifications to improve the mechanical properties and the biological response to orthopedic and dental implants: a review, Biomed. Res. Int. 2016 (2016) 2908570.

[6] M. Abdel-Hady Gepreel, M. Niinomi, Biocompatibility of Ti-alloys for long-term implantation, J. Mech. Behav. Biomed. Mater. 20 (2013) 407-415.

[7] J.M. Cordeiro, V.A.R. Barao, Is there scientific evidence favoring the substitution of commercially pure titanium with titanium alloys for the manufacture of dental implants? Mater. Sci. Eng. C Mater. Biol. Appl. 71 (2017) 1201-1215.

[8] C. Leyens, M. Peters, Titanium and Titanium Alloys, Wiley-VCH, Weinheim, 2003.

[9] D.R.N. Correa, F.B. Vicente, T.A.G. Donato, V.E. Arana-Chavez, M.A.R. Buzalaf, C.R. Grandini, The effect of the solute on the structure, selected mechanical properties, and biocompatibility of Ti-Zr system alloys for dental applications, Mater. Sci. Eng. C Mater. Biol. Appl. 34 (2014) 354-359.

[10] F.B. Vicente, D.R.N. Correa, T.A.G. Donato, V.E. Arana-Chavez, M.A.R. Buzalaf,
C.R. Grandini, The influence of small quantities of oxygen in the structure, microstructure, hardness, elasticity modulus and cytocompatibility of Ti-Zr alloys for dental applications, Materials 7 (2014) 542-553.

[11] H.-C. Hsu, C. Wu, Y.-C. Sung, W.-F. Ho, The structure and mechanical properties of as-cast Zr-Ti alloys, J. Alloys Compd. 488 (2009) 279-283.

[12] D.R.N. Correa, P.A.B. Kuroda, C.R. Grandini, Structure, microstructure, and selected mechanical properties of Ti-Zr-Mo alloys for biomedical applications, Adv. Mater. Res. 922 (2014) 75-80.

[13] J.R.S. Martins Júnior, R.A. Nogueira, R.O.d. Araújo, T.A.G. Donato, V.E. AranaChavez, A.P.R.A. Claro, J.C.S. Moraes, M.A.R. Buzalaf, C.R. Grandini, Preparation and characterization of Ti-15Mo alloy used as biomaterial, Mater. Res. 14 (2011) $107-112$

[14] D.R.N. Correa, P.A.B. Kuroda, C.R. Grandini, L.A. Rocha, F.G.M. Oliveira, A.C. Alves, F. Toptan, Tribocorrosion behavior of $\beta$-type Ti-15Zr-based alloys, Mater. Lett. 179 (2016) 118-121.

[15] D.R.N. Correa, F.B. Vicente, R.O. Araújo, M.L. Lourenço, P.A.B. Kuroda, M.A.R. Buzalaf, C.R. Grandini, Effect of the substitutional elements on the microstructure of the Ti-15Mo-Zr and Ti-15Zr-Mo systems alloys, J. Mater. Res. Technol. 4 (2015) 180-185.

[16] D.R.N. Correa, P.A.B. Kuroda, M.L. Lourenço, C.J.C. Fernandes, M.A.R. Buzalaf, W.F. Zambuzzi, C.R. Grandini, Development of Ti-15Zr-Mo alloys for applying as implantable biomedical devices, Submitted to Biomed. Mater. 749 (2018) 163-171.

[17] Q. Guo, Y. Zhan, H. Mo, G. Zhang, Aging response of the Ti-Nb system biomaterials with $\beta$-stabilizing elements, Mater. Des. 31 (2010) 4842-4846.

[18] C. Xiong, P. Xue, B. Sun, Y. Li, Effect of annealing temperature on the microstructure and superelasticity of Ti-19Zr-10Nb-1Fe alloy, Mater. Sci. Eng. A 688 (2017) 464-469.

[19] Y. Mantani, Y. Takemoto, M. Hida, A. Sakakibara, M. Tajima, Phase transformations of a" martensite structure by aging in Ti-8mass\%Mo alloy, Mater. Trans. 45 (2004) 1629-1634.

[20] M. Tane, K. Hagihara, M. Ueda, T. Nakano, Y. Okuda, Elastic-modulus enhancement during room-temperature aging and its suppression in metastable Ti-Nb-based alloys with low body-centered cubic phase stability, Acta Mater. 102 (2016) 373-384.

[21] Q. Li, M. Niinomi, M. Nakai, Z. Cui, S. Zhu, X. Yang, Effect of Zr on super-elasticity and mechanical properties of Ti-24at $\% \mathrm{Nb}-(0,2,4)$ at $\% \mathrm{Zr}$ alloy subjected to aging treatment, Mater. Sci. Eng. A 536 (2012) 197-206.

[22] S.X. Liang, X.J. Feng, L.X. Yin, X.Y. Liu, M.Z. Ma, R.P. Liu, Development of a new beta Ti alloy with low modulus and favorable plasticity for implant material, Mater. Sci. Eng. C Mater. Biol. Appl. 61 (2016) 338-343. 
[23] L.B. McCusker, R.B. Von Dreele, D.E. Cox, D. Louër, P. Scardi, Rietveld refinement guidelines, J. Appl. Crystallogr. 32 (1999) 36-50.

[24] A. E384-11e1, Standard Test Method for Knoop and Vickers Hardness of Materials, ASTM International, West Conshohocken, PA, 2011.

[25] A. E1876-09, Standard Test Method for Dynamic Young's Modulus, Shear Modulus, and POISSON'S Ratio by Impulse Excitation of Vibration, ASTM Interantional, West Conshohocken, PA, 2009.

[26] F1108-04, Standard Specification for Titanium-6aluminum-4vanadium Alloy castIngs for Surgical Implants (UNS R56406), ASTM International, West Conshohocken, PA, 2004.

[27] M. Nakai, M. Niinomi, T. Akahori, H. Tsutsumi, M. Ogawa, Effect of oxygen content on microstructure and mechanical properties of biomedical Ti-29Nb-13Ta-4.6Zr alloy under solutionized and aged conditions, Mater. Trans. 50 (2009) 2716-2720.

[28] F.F. Cardoso, P.L. Ferrandini, E.S.N. Lopes, A. Cremasco, R. Caram, Ti-Mo alloys employed as biomaterials: effect of composition and aging treatment on microstructure and mechanical behavior, J. Mech. Behav. Biomed. Mater. 32 (2014) $31-38$.

[29] J.R. Severino Martins, C.R. Grandini, Structural characterization of Ti-15Mo alloy used as biomaterial by Rietveld method, J. Appl. Phys. 111 (2012) 083535.

[30] S. Banumathy, R.K. Mandal, A.K. Singh, Structure of orthorhombic martensitic phase in binary Ti-Nb alloys, J. Appl. Phys. 106 (2009) 093518.

[31] B.D. Cullity, Elements of X-ray Diffraction, Addison-Wesley Publishing Company, Philiphines, 1978.

[32] Y.L. Zhou, M. Niinomi, T. Akahori, Decomposition of martensite during aging treatments and resulting mechanical properties of Ti-Ta alloys, Mater. Sci. Eng. A 384 (2004) 92-101.

[33] G. Will, Powder Diffraction: The Rietveld Method and the Two-stage Method, Springer, Berlin, 2006.

[34] W.F. Ho, C.P. Ju, J.H. Chern Lin, Structure and properties of cast binary Ti-Mo alloys, Biomaterials 20 (1999) 2115-2122.

[35] A. Dehghan-Manshadi, R.J. Dippenaar, Development of $\alpha$-phase morphologies during low temperature isothermal heat treatment of a Ti-5Al-5Mo-5V-3Cr alloy, Mater. Sci. Eng. A 528 (2011) 1833-1839.
[36] I. Weiss, S.L. Semiatin, Thermomechanical processing of beta titanium alloys - an overview, Mater. Sci. Eng. A 243 (1998) 46-65.

[37] C.M. Lee, C.P. Ju, J.H. Chern Lin, Structure-property relationship of cast Ti-Nb alloys, J. Oral Rehabil. 29 (2002) 314-322.

[38] O.M. Ivasishin, P.E. Markovsky, S.L. Semiatin, C.H. Ward, Aging response of coarseand fine-grained $\beta$ titanium alloys, Mater. Sci. Eng. A 405 (2005) 296-305.

[39] D. Kent, G. Wang, W. Wang, M.S. Dargusch, Influence of ageing temperature and heating rate on the properties and microstructure of $\beta$ Ti alloy, Ti-6Cr-5Mo-5V-4Al, Mater. Sci. Eng. A 531 (2012) 98-106.

[40] A. Cremasco, P.N. Andrade, R.J. Contieri, E.S.N. Lopes, C.R.M. Afonso, R. Caram, Correlations between aging heat treatment, $\omega$ phase precipitation and mechanical properties of a cast Ti-Nb alloy, Mater. Des. 32 (2011) 2387-2390.

[41] M. Geetha, A.K. Singh, A.K. Gogia, R. Asokamani, Effect of thermomechanical processing on evolution of various phases in Ti-Nb-Zr alloys, J. Alloys Compd. 384 (2004) 131-144.

[42] E. Sukedai, M. Shimoda, H. Nishizawa, Y. Nako, Nucleation behaviour of $\beta$ to $\omega$ phase transformations in $\beta$-type Ti-Mo alloys, Mater. Trans. 52 (2011) 324-330.

[43] P.L. Ferrandini, F.F. Cardoso, S.A. Souza, C.R. Afonso, R. Caram, Aging response of the Ti-35Nb-7Zr-5Ta and Ti-35Nb-7Ta alloys, J. Alloys Compd. 433 (2007) 207-210.

[44] C.C. Xavier, Estudo de tratamentos térmicos da liga Ti-15Zr-xMo, Programa de Pósgraduação em Ciência e Tecnologia de Materiais, UNESP, Bauru, 2017, p. 105.

[45] X. Zhao, M. Niinomi, M. Nakai, T. Ishimoto, T. Nakano, Development of high Z containing Ti-based alloys with low Young's modulus for use in removable implants, Mater. Sci. Eng. C 31 (2011) 1436-1444.

[46] B.D. Ratner, A.S. Hoffman, F.J. Schoen, J.E. Lemons, Biomaterials Science: An Introduction to Materials in Medicine, Academic Press, San Diego (CA), USA, 1996.

[47] M. Niinomi, Fatigue characteristics of metallic biomaterials, Int. J. Fatigue 29 (2007) 992-1000.

[48] M. Niinomi, T. Akahori, Improvement of the fatigue life of titanium alloys for biomedical devices through microstructural control, Expert Rev. Med. Devices 7 (2010) 481-488. 